\title{
Correlation of Mismatch Repair Deficiency with Clinicopathological Features and Programmed Death- Ligand 1 Expression in Thyroid Carcinoma
}

Xiao-Ping Chen ( $\nabla$ chen_xp2000@163.com )

Gongli Hospital of Shanghai Pudong New Area https://orcid.org/0000-0003-3048-2699

\section{Pei-pei Qiao}

Ningxia Medical University

Kai-Sai Tian

Ningxia Medical University

Li-Tao Han

Fudan University Shanghai Cancer Center

Ma Ben

Fudan University Shanghai Cancer Center

Cen-Kai Shen

Fudan University Shanghai Cancer Center

\section{Run-Yu Zhao}

Ningxia Medical University

\section{Yi Zhang}

Shanghai PuDong New Area Gongli Hospital

\section{Wenjun Wei}

Fudan University Shanghai Cancer Center

\section{Research Article}

Keywords: mismatch repair, thyroid carcinoma, PD-L1

Posted Date: January 11th, 2022

DOI: https://doi.org/10.21203/rs.3.rs-1219289/v1

License: (a) (i) This work is licensed under a Creative Commons Attribution 4.0 International License. Read Full License 


\section{Abstract \\ Background}

Mutations in DNA mismatch repair (MMR) genes associated with thyroid carcinoma (TC) have rarely been reported, especially in East Asian populations.

\section{Methods}

We examined tumor tissue from a cohort of 241 patients diagnosed with TC between 2008 and 2020. MMR proteins were detected using tissue microarray-based immunohistochemistry in order to identify MMRprotein-deficient (MMR-D) and MMR-protein-intact (MMR-I) tumors. We retrospectively summarized the clinicopathologic characteristics of patients with MMR-D TC, measured the expression of PD-L1, and recorded overall survival (OS) and other clinical outcomes.

\section{Results}

In our cohort, there were 18 (7.5\%) MMR-D (MLH1, MSH2, MSH6, and PMS2) patients, including 12 with papillary TC (PTC) (6.7\%), 2 with poorly differentiated TC (PDTC) (4.7\%), and 4 with anaplastic TC (ATC) (22.2\%). Half of them (9/18) showed a specific deletion in MSH6, and 6 of them also carried variants in the MSH6 and PMS2 gene. Survival was significantly better in patients with MMR-D ATC than in those with MMRI tumors ( $p=0.033)$. Four of the 18 MMR-D patients $(22 \%)$ were found to be PD-L1 positive. Their OS was much shorter than that of PD-L1-negative patients.

\section{Conclusions}

MMR-D and PD-L1 positivity appear to be associated with clinicopathological characteristics and prognosis in TC. The results indicate that MMR status may have important prognostic significance in TC. Therefore, immune checkpoint inhibitors that target the PD-1/PD-L1 pathway may be a treatment option for TCs.

\section{Introduction}

Thyroid cancer (TC) is one of the most common malignancies of the endocrine system, with the fifth-highest prevalence among women in the United States, and its incidence continues to increase rapidly [1]. Although most TCs follow an indolent clinical course, the metastasis rate of differentiated TC (DTC) remains very high. Further, poorly differentiated TC (PDTC) and anaplastic TC (ATC) are very aggressive tumors and are often likely to result in death $[2,3]$. For most patients, there is a lack of effective treatment. Therefore, effective immunotherapies or alternative treatments are urgently required.

Mismatch repair (MMR) is a high-fidelity mechanism that allows the maintenance of fidelity in DNA replication and mediates DNA damage-related signal transduction [4]. MMR deficiency is characterized by a decrease or increase in nucleotide repeats, which can lead to the evasion of apoptosis, development of 
malignant mutations, and tumorigenesis [5, 6]. MMR mainly involves four major proteins: MLH1, MSH2, MSH6, and PMS2 [7]. Latham et al. demonstrated that an MMR-protein-deficient (MMR-D)/microsatellite instability (MSI) status is associated with Lynch syndrome, which is an autosomal-dominant syndrome that predisposes individuals to cancer [8]. Lynch syndrome leads to an $80 \%$ lifetime risk of cancer development (multiple types) and patients with this condition therefore require life-long surveillance $[9,10]$. As a therapeutic target and potential prognostic indicator for a variety of tumors, MMR-D/MSI-H is associated with a good prognosis in colorectal cancer who are not sensitive to chemotherapy, and is associated with a poor prognosis after 5- FU-based auxiliary treatment [11]. MMR genes are known to play a role in the occurrence and development of TC [12]. Although pembrolizumab has received FDA approval for the treatment all advanced MMR-D solid tumors [13], data on the prevalence and prognostic significance of MMR-D/MSI-H in TC remains limited, especially for PDTC, ATC, and locally advanced (LA) PTC.

The Programmed cell death-1 (PD-1) and programmed cell death ligand 1 (PD-L1) axis is a crucial immune pathway, and an increase in PD-L1 levels in tumor cells or tumor-infiltrating lymphocytes causes T cell attenuation [14]. Diaz et al, found that one biomarker of the response to anti-PD-1 therapy is the tumor mutational burden (TMB), whereas the colorectal cancer subtype showing MMR-D has a significantly lower TMB and a poor response to these agents[11, 15]. In recent years, anti-PD-1/PD-L1 therapy has been found to be promising for treating advanced-stage ATC and may be a potential therapeutic strategy to treat advanced MTC medullary TC (MTC) $[16,17]$. According to reports, PD-L1 expression in the tumor microenvironment can predict the prognosis of patients with MMR-D tumors and their response to immunotherapy [18].

The present study is the first to examine the relationship between MMR and LA and dedifferentiated TC in a large cohort. The study attempted to identify the clinical features of MMR-D in papillary TC (PTC), PDTC, and ATC. The aim of the study was to explore the correlation between MMR and PD-L1 expression and to clarify the clinical outcomes of MMR-D tumors.

\section{Materials And Methods}

\section{Patients and samples}

Between 2009 and 2020, a total of 243 consecutive patients were diagnosed with TC (180 PTC, 43 PDTC, and 18 ATC) and received surgical treatment at the Fudan University Shanghai Cancer Center (FUSCC). Patient information, including sex, age, histologic type, tumor size, extrathyroidal extension, presence of lymphovascular invasion, tumor-node-metastasis (TNM) stage, and lymph node status, was obtained from pathology reports. According to the 8th AJCC system, LA PTC is defined as PTC showing obvious invasion of crucial structures. All patients provided written informed consent.

\section{TMA construction and IHC staining}

Formalin-fixed, paraffin-embedded (FFPE) blocks obtained from primary tumor specimens were used to construct a tissue microarray (TMA). Four-micron-thick sections were cut from representative tissue to create a 1.5-mm tissue core for the TMA. TMA sections were stained using hematoxylin-eosin and then processed using IHC based on the manufacturer's instructions (Runnerbio Company, Shanghai, China). Briefly, the slides 
were incubated with the following primary antibodies: anti-MLH1 rabbit monoclonal antibody (1:250, ab92312), anti-MSH2 rabbit monoclonal antibody (1:1000, ab227941), anti-MSH6 rabbit monoclonal antibody (1:500, ab92471), anti-PMS2 rabbit monoclonal antibody (1:100, ab110638), anti-PD-L1 rabbit monoclonal antibody (1:200, ab205921), and anti-PD-1 rabbit monoclonal antibody (1:500, ab137132). The slides were then incubated at $4^{\circ} \mathrm{C}$ overnight. Then, they were washed with PBS and probed with a secondary antibody for $2 \mathrm{~h}$ at $37^{\circ} \mathrm{C}$. The slides were stained with DAB and hematoxylin and dried. IHC-stained slides were screened using a KF-PRO-120 Digital Pathology Slide Scanner and viewed under a K-Viewer System, version 1.5.3.1 (Konfoong Biotech), and results were separately recorded by two experienced pathologists who were blinded to the patients' clinical data.

Based on previous studies, the loss of MLH1, MSH2, MSH6, and PMS2 expression in tumor cells was defined as complete loss of nuclear expression. In contrast, the internal control used showed normal positive nuclear staining for these proteins [12].

PD-1/PD-L1 expression was evaluated based on CPS, which was calculated as follows:

CPS $=\frac{\text { No. of PD-L1-stained cells (tumor cells, lymphocytes, and macrophages) }}{\text { Total no. of viable tumor cells }} \times 100$

As described by Kulangara et al, who developed the CPS system, a tumor cell was considered PD-L1-stained if complete or partial membrane PD-L1 staining was observed and an immune cell was considered stained if it featured any PD-1/PD-L1 staining (membrane/cytoplasm). The specimen was defined as PD-L1-positive if the CPS was $>1$ [19]. Furthermore, patients with positive PD-L1 staining were separated into low $(1 \leq \mathrm{CPS}<$ 5), moderate $(5 \leq \mathrm{CPS}<20)$, and high ( $C P S \geq 20$ ) expression groups.

\section{Evaluation of MSI}

Eighteen MMR-D FFPE specimens were tested for MSI. Testing was conducted with capillary electrophoresis in combination with fluorescence multiplex PCR (Microread Genetics Technology Co., Ltd., Beijing, China) using both tumors and corresponding normal tissues. Testing was performed for a set of 6 mononucleotide repeat markers (BAT25, BAT26, NR21, NR24, NR27, and MONO27), amelogenin, and 2 pentanucleotide-repeat loci (Penta $C$ and Penta D). Semiquantitative expression in tumors was calculated according to $\mathrm{NCl}$ guidelines [20] and compared with the expression in normal tissue for each patient.

\section{Statistical analysis}

All statistical analyses were conducted using the SPSS v24.0 software (IBM SPSS, Inc, Armonk, NY). Categorical variables were denoted as frequency (percentage) and compared using Chi-square tests or Fisher's exact tests (if appropriate). Continuous variables were expressed as median value (range) and compared using 2-sample Student's t-tests. All reported $p$ values were two-tailed, with a significance level of 0.05 .

\section{Results}




\section{Patient characteristics and IHC Patterns of the DNA MMR Proteins}

The clinical characteristics of the 241 patients who met the inclusion criteria and were enrolled for TMA analysis are shown in Table 1. MMR-D was detected in $1.1 \%$ of PTC patients, $4.7 \%$ of PDTC patients, and $22.2 \%$ of ATC patients (Figure. 1). Accordingly, a cohort of 18 patients with MMR-D tumors was obtained. 
Patient Clinicopathological Characteristics ( $N=241)$

\begin{tabular}{|c|c|c|c|c|}
\hline Clinicopathological Features & Overall cohort $(n=241)$ & MMR-D ( $n=18)$ & MMR-I $(n=223)$ & $\mathrm{p}$-Value \\
\hline \multicolumn{5}{|l|}{ Age, yr } \\
\hline Median (range) & $56(16-87)$ & $54(19-67)$ & $56(16-87)$ & 0.886 \\
\hline \multicolumn{5}{|l|}{ Sex } \\
\hline Male & $115(47.7 \%)$ & $7(38.9 \%)$ & $108(48.4 \%)$ & 0.593 \\
\hline Female & $126(52.3 \%)$ & $11(61.1 \%)$ & $115(51.6 \%)$ & \\
\hline \multicolumn{5}{|l|}{ Laterality } \\
\hline Unilateral & $181(75.1 \%)$ & $17(94.4 \%)$ & $164(73.5 \%)$ & 0.05 \\
\hline Bilateral & $60(24.9 \%)$ & $1(5.6 \%)$ & $59(26.5 \%)$ & \\
\hline \multicolumn{5}{|l|}{ Tumor size, cm } \\
\hline$\leq 2$ & $98(40.7 \%)$ & $11(61.1 \%)$ & $87(39.0 \%)$ & 0.098 \\
\hline $2.1-4$ & $87(36.1 \%)$ & $6(33.3 \%)$ & $81(36.3 \%)$ & \\
\hline$>4$ & $56(23.2 \%)$ & $1(5.6 \%)$ & $55(24.7 \%)$ & \\
\hline \multicolumn{5}{|l|}{ Multifocal } \\
\hline NO & $163(67.6 \%)$ & 15(83.3\%) & $147(65.9 \%)$ & 0.21 \\
\hline YES & $78(32.4 \%)$ & $3(16.7 \%)$ & $76(34.1 \%)$ & \\
\hline \multicolumn{5}{|l|}{ Lymphovascular invasion } \\
\hline NO & $220(91.3 \%)$ & $18(100 \%)$ & $202(90.8 \%)$ & 0.379 \\
\hline YES & $21(8.7 \%)$ & 0 & $21(9.2 \%)$ & \\
\hline \multicolumn{5}{|l|}{ Lymph node metastasis } \\
\hline \multicolumn{5}{|l|}{ CLNM } \\
\hline Negative & $90(37.3 \%)$ & $5(27.8 \%)$ & 85 (40.8\%) & 0.383 \\
\hline Positive & $151(62.7 \%)$ & $13(72.2 \%)$ & $138(61.9 \%)$ & \\
\hline \multicolumn{5}{|l|}{ LLNM } \\
\hline Negative & $100(41.5 \%)$ & $9(50 \%)$ & 91 (40.8\%) & 0.446 \\
\hline Positive & $141(58.5 \%)$ & $9(50 \%)$ & $132(59.2 \%)$ & \\
\hline
\end{tabular}

Abbreviations: CLNM, Central lymph node metastasis; LLNM, Lateral lymph node metastasis; AJCC, American Joint Committee on Cancer; HT, Hashimoto's thy-roiditis; ETE, Extrathyroidal extension; PD-L1, Programmed cell death ligand 1. 


\begin{tabular}{|c|c|c|c|c|}
\hline Clinicopathological Features & Overall cohort $(n=241)$ & MMR-D (n=18) & MMR-I (n=223) & p-Value \\
\hline I/II & $72(29.9 \%)$ & $7(38.9 \%)$ & $65(29.1 \%)$ & 0.631 \\
\hline III & $58(24.1 \%)$ & $3(16.7 \%)$ & $55(24.7 \%)$ & \\
\hline IV & $111(46.1 \%)$ & $8(44.4 \%)$ & $103(46.2 \%)$ & \\
\hline \multicolumn{5}{|l|}{ ETE } \\
\hline YES & $152(63.1 \%)$ & $11(61.1 \%)$ & $141(63.2 \%)$ & 0.858 \\
\hline NO & $89(36.9 \%)$ & $7(38.9 \%)$ & $82(36.8 \%)$ & \\
\hline \multicolumn{5}{|l|}{ HT } \\
\hline YES & $30(12.4 \%)$ & $5(27.8 \%)$ & $25(11.2 \%)$ & 0.094 \\
\hline NO & $211(87.6 \%)$ & $13(72.2 \%)$ & $198(88.8 \%)$ & \\
\hline \multicolumn{5}{|l|}{ PD-L1 expression } \\
\hline YES & $50(20.7 \%)$ & $4(22.2 \%)$ & $46(20.6 \%)$ & 0.771 \\
\hline NO & $191(79.3 \%)$ & $14(77.8 \%)$ & $177(79.4 \%)$ & \\
\hline
\end{tabular}

In this MMR-D cohort, six cases (33.33\%) showed paired MSH6 and PMS2 losses, one case showed MLH1 and MSH2 losses, one case showed MLH1 and PMS2 losses, and one case showed MSH2 and MSH6 losses. In nine cases (50.00\%), only MSH6 loss was observed (Table 2). Cases of MMR-D and MMR-I are depicted in Figure. 2. 
Table 2

Clinical Characteristics, Treatment, and Recurrence of Patients with MMR-D

\begin{tabular}{|c|c|c|c|c|c|c|c|}
\hline $\begin{array}{l}\text { Patient } \\
\text { ID }\end{array}$ & $\begin{array}{l}\text { Pathological } \\
\text { type }\end{array}$ & Age & $\begin{array}{l}\text { MMR } \\
\text { Status }\end{array}$ & Gene & MSI status & $\begin{array}{l}\text { Initial } \\
\text { Treatment } \\
\text { Received }\end{array}$ & $\begin{array}{l}\text { Recurrence } \\
(\mathrm{Y} / \mathrm{N})\end{array}$ \\
\hline 1 & PTC & 56 & $\begin{array}{l}\text { MMR- } \\
\text { D }\end{array}$ & MLH1/PMS2 & MSI-L NR21 & $\begin{array}{l}\text { surgery } \\
\text { alone }\end{array}$ & $\mathrm{N}$ \\
\hline 2 & LA & 55 & $\begin{array}{l}\text { MMR- } \\
\text { D }\end{array}$ & MLH1/MSH2 & MSS & $\begin{array}{l}\text { surgery and } \\
1131\end{array}$ & Y \\
\hline 3 & ATC & 67 & $\begin{array}{l}\text { MMR- } \\
\text { D }\end{array}$ & MSH2/MSH6 & NA & $\begin{array}{l}\text { surgery and } \\
\text { radiotherapy }\end{array}$ & Y \\
\hline 4 & PTC & 48 & $\begin{array}{l}\text { MMR- } \\
\text { D }\end{array}$ & MSH6/PMS2 & MSS & $\begin{array}{l}\text { surgery } \\
\text { alone }\end{array}$ & $\mathrm{N}$ \\
\hline 5 & PTC & 24 & $\begin{array}{l}\text { MMR- } \\
\text { D }\end{array}$ & MSH6/PMS2 & MSS & $\begin{array}{l}\text { surgery } \\
\text { alone }\end{array}$ & $\mathrm{N}$ \\
\hline 6 & PTC & 19 & $\begin{array}{l}\text { MMR- } \\
\text { D }\end{array}$ & MSH6/PMS2 & MSS & $\begin{array}{l}\text { surgery } \\
\text { alone }\end{array}$ & $\mathrm{N}$ \\
\hline 7 & PTC & 53 & $\begin{array}{l}\text { MMR- } \\
\text { D }\end{array}$ & MSH6/PMS2 & NA & $\begin{array}{l}\text { surgery } \\
\text { alone }\end{array}$ & $\mathrm{N}$ \\
\hline 8 & ATC & 63 & $\begin{array}{l}\text { MMR- } \\
\text { D }\end{array}$ & MSH6/PMS2 & MSS & $\begin{array}{l}\text { Surgery and } \\
\text { radiotherapy }\end{array}$ & $\mathrm{Y}$ \\
\hline 9 & PTC & 49 & $\begin{array}{l}\text { MMR- } \\
\text { D }\end{array}$ & MSH6/PMS2 & $\begin{array}{l}\text { MSI-H } \\
\text { NR21.Mono27 }\end{array}$ & $\begin{array}{l}\text { surgery } \\
\text { alone }\end{array}$ & $\mathrm{N}$ \\
\hline 10 & PTC & 50 & $\begin{array}{l}\text { MMR- } \\
\text { D }\end{array}$ & MSH6 & MSI-L BAT26 & $\begin{array}{l}\text { surgery } \\
\text { alone }\end{array}$ & Y \\
\hline 11 & PDTC & 65 & $\begin{array}{l}\text { MMR- } \\
\text { D }\end{array}$ & MSH6 & NA & $\begin{array}{l}\text { surgery, } \\
\text { I131, Chemo } \\
\text { and } \\
\text { radiotherapy }\end{array}$ & Y \\
\hline 12 & PDTC & 47 & $\begin{array}{l}\text { MMR- } \\
\text { D }\end{array}$ & MSH6 & NA & $\begin{array}{l}\text { surgery } \\
\text { alone }\end{array}$ & $\mathrm{N}$ \\
\hline 13 & PTC & 61 & $\begin{array}{l}\text { MMR- } \\
\text { D }\end{array}$ & MSH6 & MSS & $\begin{array}{l}\text { surgery } \\
\text { alone }\end{array}$ & $\mathrm{N}$ \\
\hline 14 & PTC & 45 & $\begin{array}{l}\text { MMR- } \\
\text { D }\end{array}$ & MSH6 & MSS & $\begin{array}{l}\text { surgery } \\
\text { alone }\end{array}$ & $\mathrm{N}$ \\
\hline 15 & PTC & 47 & $\begin{array}{l}\text { MMR- } \\
\text { D }\end{array}$ & MSH6 & NA & $\begin{array}{l}\text { surgery } \\
\text { alone }\end{array}$ & $\mathrm{N}$ \\
\hline 16 & ATC & 59 & $\begin{array}{l}\text { MMR- } \\
\text { D }\end{array}$ & MSH6 & MSS & $\begin{array}{l}\text { surgery } \\
\text { alone }\end{array}$ & Y \\
\hline
\end{tabular}




\begin{tabular}{|llclllll|}
\hline $\begin{array}{l}\text { Patient } \\
\text { ID }\end{array}$ & $\begin{array}{l}\text { Pathological } \\
\text { type }\end{array}$ & Age & $\begin{array}{l}\text { MMR } \\
\text { Status }\end{array}$ & Gene & MSI status & $\begin{array}{l}\text { Initial } \\
\text { Treatment } \\
\text { Received }\end{array}$ & $\begin{array}{c}\text { Recurrence } \\
\text { (Y/N) }\end{array}$ \\
\hline 17 & ATC & 64 & $\begin{array}{l}\text { MMR- } \\
\text { D }\end{array}$ & MSH6 & MSS & $\begin{array}{l}\text { surgery } \\
\text { alone }\end{array}$ & $\mathrm{Y}$ \\
\hline 18 & PTC & 63 & $\begin{array}{l}\text { MMR- } \\
\text { D }\end{array}$ & MSH6 & NA & $\begin{array}{l}\text { surgery } \\
\text { alone }\end{array}$ & $\mathrm{N}$ \\
\hline $\begin{array}{l}\text { Abbreviations: MMR-D, MMR-protein-deficient; PTC, papillary thyroid carcinoma; LA, locally advanced; } \\
\text { PDTC, poorly differentiated poorly differentiated thyroid carcinoma; ATC, anaplastic thyroid carcinoma; } \\
\text { MSI, microsatellite instability; MSS, microsatellite stability; NA, not available. }\end{array}$ & \\
\hline
\end{tabular}

\section{MSI testing in 18 patients with MMR-D}

We performed MSI detection for 18 cases of MMR-D: one case showed MSI-H, two cases showed MSI-L, and nine cases showed MSS; in six cases, analysis could not be performed owing to limited DNA availability. High MSI instability was detected with both NR21 and Mono27 mononucleotide markers. BAT26 and NR21 variants were detected in two other cases of MMR-D (Table 2), and none of the patients had Lynch syndrome or a related family history.

\section{Association between MMR expression and overall survival (OS) in TCs}

MMR-D ( $(\mathrm{N}=18)$ and MMR-protein-intact $(M M R-I)$ patients $(\mathrm{N}=223)$ (Table 1) were compared. For each patient enrolled in this study, at least one follow-up conversation or visit was performed. Moreover, survival data for 234 of 241 patients' (97.1\%) was obtained through these follow-ups. The maximum follow-up duration was 176 months. During the follow-up, there were 49 deaths (20.9\%); of the patients who died, 12 had PTC, 23 had PDTC, and 14 had ATC. The mortality rates for PDTC and ATC were relatively high, reaching $53.5 \%(23 / 43)$ and $77.8 \%(14 / 18)$, respectively.

Moreover, 4 of 4 (100\%) MMR-D ATC patients and 10 of the 14 (71.4\%) MMR-I ATC patients died. However, MMR-D ATC patients tended to have better OS than their MMR-I counterparts $(p=0.032$; Fig. 4$)$. Univariate Cox analysis showed that PD-L1 expression (HR $=1.04,95 \% \mathrm{Cl}: 1.02-1.07, p<0.001)$ and lateral lymph node metastasis (LLNM) $(\mathrm{HR}=2.902,95 \% \mathrm{Cl}: 1.068-7.891, p=0.037)$ were independent predictors of OS in PTC and PDTC, respectively. Extrathyroidal extension (HR $=3.69,95 \% \mathrm{Cl}: 1.045-13.02, p=0.04)$ and MMR-D (HR = $5.472,95 \% \mathrm{Cl}: 1.145-26.146, p<0.001)$ appeared to be independent predictors of OS in ATC and were included in the subsequent multivariate Cox regression analysis (Table 3 ). 
Table 3

Univariate and multivariate Cox analysis of prognostic factors for structural recurrence-free survival in 241 all cohort

\begin{tabular}{|c|c|c|c|c|c|}
\hline \multirow[t]{2}{*}{ Variables } & & \multicolumn{2}{|l|}{ Univariate analysis } & \multicolumn{2}{|l|}{$\begin{array}{l}\text { Multivariate } \\
\text { analysis }\end{array}$} \\
\hline & & $\mathrm{HR}(95 \% \mathrm{Cl})$ & $P$ & $\mathrm{HR}(95 \% \mathrm{Cl})$ & $P$ \\
\hline \multirow[t]{3}{*}{ Male vs female } & PTC & $1.243(0.39-3.967)$ & 0.713 & & \\
\hline & PDTC & $1.054(0.447-2.484)$ & 0.904 & & \\
\hline & ATC & $1.126(0.354-3.58)$ & 0.84 & & \\
\hline \multirow[t]{3}{*}{ Age $<65$ y vs $\geq 65 y$} & PTC & $1.468(0.291-7.393)$ & 0.642 & & \\
\hline & PDTC & $0.516(0.182-1.464)$ & 0.214 & & \\
\hline & ATC & $1.00(0.98-1.03)$ & 0.741 & & \\
\hline \multicolumn{6}{|l|}{ Tumor size, cm } \\
\hline \multirow[t]{2}{*}{ PTC } & $\begin{array}{l}2.1-4 \text { vs } \leq \\
2\end{array}$ & $0.923(0.111-7.696)$ & 0.941 & & \\
\hline & $>4$ vs $\leq 2$ & $\begin{array}{l}1.256(0.144- \\
10.922)\end{array}$ & 0.836 & & \\
\hline \multirow[t]{2}{*}{ PDTC } & $\begin{array}{l}2.1-4 \text { vs } \leq \\
2\end{array}$ & $0.706(0.24-2.076)$ & 0.527 & & \\
\hline & $>4$ vs $\leq 2$ & 1.673 (0.527-5.309) & 0.383 & & \\
\hline \multirow[t]{2}{*}{ ATC } & $\begin{array}{l}2.1-4 \text { vs } \leq \\
2\end{array}$ & $\begin{array}{l}1.571(0.175- \\
14.114)\end{array}$ & 0.687 & & \\
\hline & $>4$ vs $\leq 2$ & $1.43(0.171-11.982)$ & 0.741 & & \\
\hline Extrathyroidal extension & PTC & $0.718(0.215-2.389)$ & 0.589 & & \\
\hline \multirow[t]{2}{*}{ Yes vs no } & PDTC & $1.603(0.653-3.936)$ & 0.303 & & \\
\hline & ATC & $3.69(1.045-13.024)$ & 0.042 & $2.07(0.553-7.758)$ & 0.3 \\
\hline Concomitant HT & PTC & $1.135(0.144-8.922)$ & 0.904 & & \\
\hline \multirow[t]{2}{*}{ No vs yes } & PDTC & $1.257(0.271-5.819)$ & 0.77 & & \\
\hline & ATC & $0.891(0.191-4.162)$ & 0.884 & & \\
\hline Multifocal & PTC & $\begin{array}{l}4.413(0.568- \\
34.302)\end{array}$ & 0.156 & & \\
\hline
\end{tabular}

Abbreviations: HR, hazard ratio; PTC, papillary thyroid carcinoma; PDTC, poorly differentiated thyroid carcinoma; ATC, anaplastic thyroid carcinoma; CLNM, Central lymph node metastasis; LLNM, Lateral lymph node metastasis; AJCC, American Joint Committee on Cancer; HT, Hashimoto's thyroiditis; MSI, microsatellite instability; PD-L1, Programmed cell death ligand 1. 


\begin{tabular}{|c|c|c|c|c|}
\hline Variables & & Univariate analysis & & $\begin{array}{l}\text { Multivariate } \\
\text { analysis }\end{array}$ \\
\hline \multirow{2}{*}{$\begin{array}{l}\text { Unifocality vs } \\
\text { Multifocality }\end{array}$} & PDTC & $0.776(0.504-1.193)$ & 0.248 & \\
\hline & ATC & $0.59(0.177-1.968)$ & 0.391 & \\
\hline $\begin{array}{l}\text { Lymphovascular } \\
\text { invasion }\end{array}$ & PTC & $0.342(0.042-2.774)$ & 0.315 & \\
\hline \multirow[t]{2}{*}{ Yes vs no } & PDTC & $1.794(0.632-5.094)$ & 0.272 & \\
\hline & ATC & $1.61(0.86-3.03)$ & 0.205 & \\
\hline Laterality & PTC & $1.844(0.403-8.439)$ & 0.43 & \\
\hline \multirow[t]{2}{*}{ Bilateral vs unilateral } & PDTC & $1.967(0.813-4.763)$ & 0.134 & \\
\hline & ATC & $0.29(0.057-1.48)$ & 0.137 & \\
\hline Lymph node metastasis & PTC & $0.783(0.235-2.611)$ & 0.691 & \\
\hline \multirow[t]{2}{*}{ CLNM } & PDTC & $2.458(0.814-7.419)$ & 0.111 & \\
\hline & ATC & $1.433(0.459-4.47)$ & 0.536 & \\
\hline LLNM & PTC & $0.137(0.018-1.063)$ & 0.057 & \\
\hline \multirow[t]{2}{*}{ Yes vs no } & PDTC & $2.902(1.068-7.891)$ & 0.037 & \\
\hline & ATC & $0.946(0.307-2.92)$ & 0.923 & \\
\hline MSI & PTC & $0.876(0.113-6.8)$ & 0.899 & \\
\hline \multirow[t]{2}{*}{ Yes vs no } & PDTC & $0.885(0.117-6.666)$ & 0.906 & \\
\hline & ATC & $\begin{array}{l}5.472(1.145- \\
26.146)\end{array}$ & 0.033 & $\begin{array}{l}4.244(0.799- \\
22.553)\end{array}$ \\
\hline PD-L1 expression & PTC & $1.04(1.02-1.07)$ & $\begin{array}{l}< \\
0.001\end{array}$ & \\
\hline \multirow[t]{2}{*}{ Positive vs negative } & PDTC & $0.625(0.273-1.431)$ & 0.266 & \\
\hline & ATC & $1.006(0.993-1.019)$ & 0.384 & \\
\hline
\end{tabular}

\section{Correlation between MMR-D and PD-1/PD-L1 expressions in TCs}

Based on IHC staining, we observed that 50 patients from the overall cohort (20.7\%) showed positive expression for PD-L1 in tumor tissues (13, 11, and 26 showing low, medium, and high expression, 
respectively). Of the 4 (22.2\%) PD-L1-positive MMR-D patients, 1 and 3 showed medium and high expression of PD-L1, respectively. PD-1 positive expression accounts for only one case. Representative images showing PD-L1 expression are shown in Figure. 3.

We observed that 4 of the 18 MMR-D patients (22\%) were PD-L1-positive, and their OS was much shorter than that of PD-L1-negative patients. Moreover, their OS was associated with their CPS values. In the log-rank test, significant differences in OS were observed between PD-L1-negative and -positive patients, and a significant difference was also observed among the negative/low, moderate, and high expression groups (both $p<$ 0.001) (Figure. 5).

\section{Discussion}

In this study, we identified MMR-D TCs and investigated their mutation profiles, clinicopathological features, and prognostic significance. Previous studies have shown that the MMR-D phenotype occurs not only in hereditary non-polyposis CRC but also in endometrial cancer and breast cancer [21-23]. Mutations in MMR genes have been reported in approximately $14 \%$ of ATC cases [12]. We examined the rate of MMR-D tumors in patients with PTC (6.7\%), PDTC (4.7\%), and ATC (22.2\%), and our findings were in line with the results of two prior studies that evaluated the genetic landscape of TCs $[12,24]$.

Our cohort contained some cases wherein two MMR proteins were deficient (MLH1 and PMS2, MLH1 and MSH2, MSH2 and MSH6, MSH6 and PMS2), and our results showed a higher proportion of MSH6 and PMS2 loss. Latham et al. noted that $20 \%(2 / 10)$ of small bowel adenocarcinoma (SBA) patients harbored PMS2 germline mutations, and suggesting that these mutations drove the malignancy [25]. Sugano highlighted that homozygous mutations in the PMS2 gene were related to early-onset gastrointestinal adenocarcinoma ( 20 years), multiple adenomatous polyps, childhood brain lymphoma/leukemia, and neurofibromatosis type 1 $[26,27]$.

In this study, we observed MSI in 3 cases. It is worth noting that 1 of the included tumors was assessed for MSI-H/MMR-D and 2 were assessed for MSI-L/MMR-D status. Studies on SBA, endometrial cancer, and CRC have reported differences between MSI testing and IHC [21, 22, 25]. The other 11 cases showed microsatellite stability (MSS). MLH1/PMS2 and MSH6 expression losses due to germline or somatic DNA variants in MLH1 or due to MLH1 promoter hypermethylation. MSH2/MSH6 expression losses due to germline or somatic DNA variants. Solitary MSH6 losses due to germline or somatic DNA variants[25]. In these patients, there was no history of preoperative radiotherapy, although MSH6 protein expression has been reported to be lost after neoadjuvant radiation[28]. Moreover, it is known that MMR protein loss typically corresponds to MLH1 promoter hypermethylation and MSI within small portions of tumors[29]. The advantage of IHC is the ability to detect MMR-D cases that can potentially be missed by MSI testing, specifically for MSH6 mutations, which tend to cause weak or no MSI in endometrial carcinomas[30].

Our data also demonstrated that MMR-D may be associated with better disease prognosis, especially in stage IVB ATC [12] and stage III CRC [31]. Related studies have also demonstrated that the improvement in survival rate may be due to the enhanced anti-tumor immune response caused by an increased neoantigen load resulting from the hypermutation phenotype of MMR-D tumors [32]. Konishi et al pointed out that MMR CRC 
with a better prognosis may have fewer mutations in p53 $[12,33]$ and more frequent mutations in the $\beta$ catenin, transforming growth factor $\beta$ receptor type II genes [34], and the intense lymphocytic infiltrates observed in tumors [35]. The penetrance of MSH6 and PMS2 mutations in CRC has been controversial because these mutations do not significantly increase the risk of extracolonic malignancies[36].

We found that 22\% of MMR-D patients were PD-L1-positive, and OS analysis shows that a PD-L1-positive MMR-D phenotype was linked to a poor prognosis. Previous research has shown a positive rate of $14.4 \%$ among MTC patients. The five-year structural recurrence-free survival rate of patients with PD-L1-positive tumors has been reported to be nearly $28 \%$ lower than that of those with PD-L1-negative tumors[16]. MMR status is correlated with an increased neoantigen load, causing stronger immune responses and the upregulation of immune checkpoints, including PD-1/PD-L1. Hence, positive patients are generally more likely to obtain a survival benefit from ICls [20,37]. Although nivolumab has been approved by the FDA for the treatment of adult and pediatric patients (age $\geq 12$ years)[38], a multicenter study that investigated the combination of nivolumab and ipilimumab in MMR-D/MSI-H CRC patients reported an overall response rate of 55\%[39]. A more comprehensive assessment of MMR/MSI, PD-1/PD-L1 expression, TMB, and T-cellinflamed gene expression profile (GEP) could help in improved identification of patients with higher odds of responding to ICls in future clinical trials for advanced TCs.

There are some limitations to the present study. First, although the sample size was large in terms of TC cases, considering the retrospective nature of the study, further research is still warranted. Second, MMR associated gene mutations may need to be further involved in the present study, including mutations in the GTPase (KRAS), KRAS proto-oncogene, and serine/threonine kinase (BRAF). Finally, it is necessary to further performed next-generation sequencing along with targeted gene sequencing or whole exome/genome sequencing for cases with MMR IHC results to infer the MMR genotype status.

Overall, we have depicted the DNA MMR and PD-L1 expression patterns in TC patients in the present study. A comprehensive analysis of multiple markers could help in the development of optimal strategies for identifying patients with LA, PDTC, and ATC sensitive to immunotherapy in the near future.

\section{Declarations}

\section{Data Availability}

The datasets generated during and/or analysed during the current study are available from the corresponding author on reasonable request.

\section{Compliance with ethical standards}

Conflict of interest The authors declare no competing interests.

Ethical approval This study was performed with the approval of the ethics committee of the Fudan University Shanghai Cancer Center.

Informed consent Informed consent was obtained from all individual participants included in the study. 


\section{Financial Support}

This work was supported by the Shanghai Natural Science Foundation (No. 19ZR1410900 to W.J.W.), the Key Medical Specialty Construction Project of Shanghai (No: ZK2019C6), and the Key Subspecialty of Thyroid Head and Neck Tumors (No: PWZy2020-06).

\section{References}

1. M.E. Cabanillas, D.G. McFadden, Durante C Thyroid cancer. Lancet 388, 2783-2795 (2016)

2. E.B. Flink, The thyroid gland. Environ Health Perspect 38, 55-56 (1981)

3. S.N. Rao, M. Zafereo, R. Dadu, N.L. Busaidy, K. Hess et al., Patterns of Treatment Failure in Anaplastic Thyroid Carcinoma. Thyroid 27, 672-681 (2017)

4. P. Hsieh, Yamane K DNA mismatch repair: molecular mechanism, cancer, and ageing. Mech Ageing Dev 129, 391-407 (2008)

5. M.J. Overman, R. McDermott, J.L. Leach, S. Lonardi, H.J. Lenz et al., Nivolumab in patients with metastatic DNA mismatch repair-deficient or microsatellite instability-high colorectal cancer (CheckMate 142): an open-label, multicentre, phase 2 study. Lancet Oncol. 18, 1182-1191 (2017)

6. C. Luchini, F. Bibeau, M.J.L. Ligtenberg, N. Singh, A. Nottegar et al., ESMO recommendations on microsatellite instability testing for immunotherapy in cancer, and its relationship with PD-1/PD-L1 expression and tumour mutational burden: a systematic review-based approach. Ann. Oncol. 30, 12321243 (2019)

7. G.M. Li, Mechanisms and functions of DNA mismatch repair. Cell Res. 18, 85-98 (2008)

8. A. Latham, P. Srinivasan, Y. Kemel, J. Shia, C. Bandlamudi et al., Microsatellite Instability Is Associated With the Presence of Lynch Syndrome Pan-Cancer. J. Clin. Oncol. 37, 286-295 (2019)

9. H. Hampel, W.L. Frankel, E. Martin, M. Arnold, K. Khanduja et al., Screening for the Lynch syndrome (hereditary nonpolyposis colorectal cancer). N. Engl. J. Med. 352, 1851-1860 (2005)

10. H. Hampel, W.L. Frankel, E. Martin, M. Arnold, K. Khanduja et al., Feasibility of screening for Lynch syndrome among patients with colorectal cancer. J. Clin. Oncol. 26, 5783-5788 (2008)

11. H. Kawakami, A. Zaanan, F.A. Sinicrope, Microsatellite instability testing and its role in the management of colorectal cancer. Curr. Treat. Options Oncol. 16, 30 (2015)

12. K.S. Wong, J.H. Lorch, E.K. Alexander, M.A. Nehs, J.A. Nowak et al., Clinicopathologic Features of Mismatch Repair-Deficient Anaplastic Thyroid Carcinomas. Thyroid 29, 666-673 (2019)

13. V. Prasad, V. Kaestner, S. Mailankody, Cancer Drugs Approved Based on Biomarkers and Not Tumor TypeFDA Approval of Pembrolizumab for Mismatch Repair-Deficient Solid Cancers. JAMA Oncol 4, 157-158 (2018)

14. A. Kythreotou, A. Siddique, F.A. Mauri, M. Bower, D.J. Pinato, Pd-L1. J. Clin. Pathol. 71, 189-194 (2018)

15. L.A. Diaz Jr., Le DT PD-1 Blockade in Tumors with Mismatch-Repair Deficiency. N. Engl. J. Med. 373, 1979 (2015) 
16. X. Shi, P.C. Yu, B.W. Lei, C.W. Li, Y. Zhang et al., Association Between Programmed Death-Ligand 1 Expression and Clinicopathological Characteristics, Structural Recurrence, and Biochemical Recurrence/Persistent Disease in Medullary Thyroid Carcinoma. Thyroid 29, 1269-1278 (2019)

17. J. Capdevila, L.J. Wirth, T. Ernst, S. Ponce Aix, C.C. Lin et al., PD-1 Blockade in Anaplastic Thyroid Carcinoma. J. Clin. Oncol. 38, 2620-2627 (2020)

18. M. Yi, D. Jiao, H. Xu, Q. Liu, W. Zhao et al., Biomarkers for predicting efficacy of PD-1/PD-L1 inhibitors. Mol Cancer 17, 129 (2018)

19. K. Kulangara, N. Zhang, E. Corigliano, L. Guerrero, S. Waldroup et al., Clinical Utility of the Combined Positive Score for Programmed Death Ligand-1 Expression and the Approval of Pembrolizumab for Treatment of Gastric Cancer. Arch Pathol Lab Med 143, 330-337 (2019)

20. M. Baretti, Le DT DNA mismatch repair in cancer. Pharmacol Ther 189, 45-62 (2018)

21. R. Doghri, Y. Houcine, N. Boujelbene, M. Driss, L. Charfi et al., Mismatch Repair Deficiency in Endometrial Cancer: Immunohistochemistry Staining and Clinical Implications. Appl. Immunohistochem. Mol. Morphol. 27, 678-682 (2019)

22. N.B. Schneider, T. Pastor, A.E. Paula, M.I. Achatz, A.R.D. Santos et al., Germline MLH1, MSH2 and MSH6 variants in Brazilian patients with colorectal cancer and clinical features suggestive of Lynch Syndrome. Cancer Med 7, 2078-2088 (2018)

23. M.E. Roberts, S.A. Jackson, L.R. Susswein, N. Zeinomar, X. Ma et al., MSH6 and PMS2 germ-line pathogenic variants implicated in Lynch syndrome are associated with breast cancer. Genet Med 20, 1167-1174 (2018)

24. I. Landa, T. Ibrahimpasic, L. Boucai, R. Sinha, J.A. Knauf et al., Genomic and transcriptomic hallmarks of poorly differentiated and anaplastic thyroid cancers. J. Clin. Invest. 126, 1052-1066 (2016)

25. A. Latham, J. Shia, Z. Patel, D.L. Reidy-Lagunes, N.H. Segal et al., Characterization and Clinical Outcomes of DNA Mismatch Repair-deficient Small Bowel Adenocarcinoma. Clin Cancer Res 27, 1429-1437 (2021)

26. K. Sugano, T. Nakajima, S. Sekine, H. Taniguchi, S. Saito et al., Germline PMS2 mutation screened by mismatch repair protein immunohistochemistry of colorectal cancer in Japan. Cancer Sci 107, 16771686 (2016)

27. C.A. Durno, P.M. Sherman, M. Aronson, D. Malkin, C. Hawkins et al., Phenotypic and genotypic characterisation of biallelic mismatch repair deficiency (BMMR-D) syndrome. Eur. J. Cancer 51, 977-983 (2015)

28. J.B. Goldstein, W. Wu, E. Borras, G. Masand, A. Cuddy et al., Can Microsatellite Status of Colorectal Cancer Be Reliably Assessed after Neoadjuvant Therapy? Clin Cancer Res 23, 5246- 5254 (2017)

29. E. Stelloo, A.M.L. Jansen, E.M. Osse, R.A. Nout, C.L. Creutzberg et al., Practical guidance for mismatch repair-deficiency testing in endometrial cancer. Ann. Oncol. 28, 96-102 (2017)

30. M.K. McConechy, A. Talhouk, H.H. Li-Chang, S. Leung, D.G. Huntsman et al., Detection of DNA mismatch repair (MMR) deficiencies by immunohistochemistry can effectively diagnose the microsatellite instability (MSI) phenotype in endometrial carcinomas. Gynecol. Oncol. 137, 306-310 (2015)

31. J. Taieb, Q. Shi, L. Pederson, S. Alberts, N. Wolmark et al., Prognosis of microsatellite instability and/or mismatch repair deficiency stage III colon cancer patients after disease recurrence following adjuvant 
treatment: results of an ACCENT pooled analysis of seven studies. Ann. Oncol. 30, 1466-1471 (2019)

32. C. Guastadisegni, M. Colafranceschi, L. Ottini, E. Dogliotti, Microsatellite instability as a marker of prognosis and response to therapy: a meta-analysis of colorectal cancer survival data. Eur. J. Cancer 46, 2788-2798 (2010)

33. M. Konishi, R. Kikuchi-Yanoshita, K. Tanaka, M. Muraoka, A. Onda et al., Molecular nature of colon tumors in hereditary nonpolyposis colon cancer, familial polyposis, and sporadic colon cancer. Gastroenterology 111, 307-317 (1996)

34. S. Markowitz, J. Wang, L. Myeroff, R. Parsons, L. Sun et al., Inactivation of the type II TGF-beta receptor in colon cancer cells with microsatellite instability. Science 268, 1336-1338 (1995)

35. H. Kim, J. Jen, B. Vogelstein, S.R. Hamilton, Clinical and pathological characteristics of sporadic colorectal carcinomas with DNA replication errors in microsatellite sequences. Am. J. Pathol. 145, 148156 (1994)

36. M. Dominguez-Valentin, J.R. Sampson, T.T. Seppala, S.W. Ten Broeke, J.P. Plazzer et al., Cancer risks by gene, age, and gender in 6350 carriers of pathogenic mismatch repair variants: findings from the Prospective Lynch Syndrome Database. Genet Med 22, 15-25 (2020)

37. F. Loupakis, G. Maddalena, I. Depetris, S. Murgioni, F. Bergamo et al., Treatment with checkpoint inhibitors in a metastatic colorectal cancer patient with molecular and immunohistochemical heterogeneity in MSI/dMMR status. J Immunother Cancer 7, 297 (2019)

38. T. Yoshino, G. Pentheroudakis, S. Mishima, M.J. Overman, K.H. Yeh et al., JSCO-ESMO-ASCO-JSMO-TOS: international expert consensus recommendations for tumour-agnostic treatments in patients with solid tumours with microsatellite instability or NTRK fusions. Ann. Oncol. 31, 861-872 (2020)

39. M.J. Overman, S. Lonardi, K.Y.M. Wong, H.J. Lenz, F. Gelsomino et al., Durable Clinical Benefit With Nivolumab Plus Ipilimumab in DNA Mismatch Repair-Deficient/Microsatellite Instability-High Metastatic Colorectal Cancer. J. Clin. Oncol. 36, 773-779 (2018)

\section{Figures}




\section{Overall Distribution of Results}

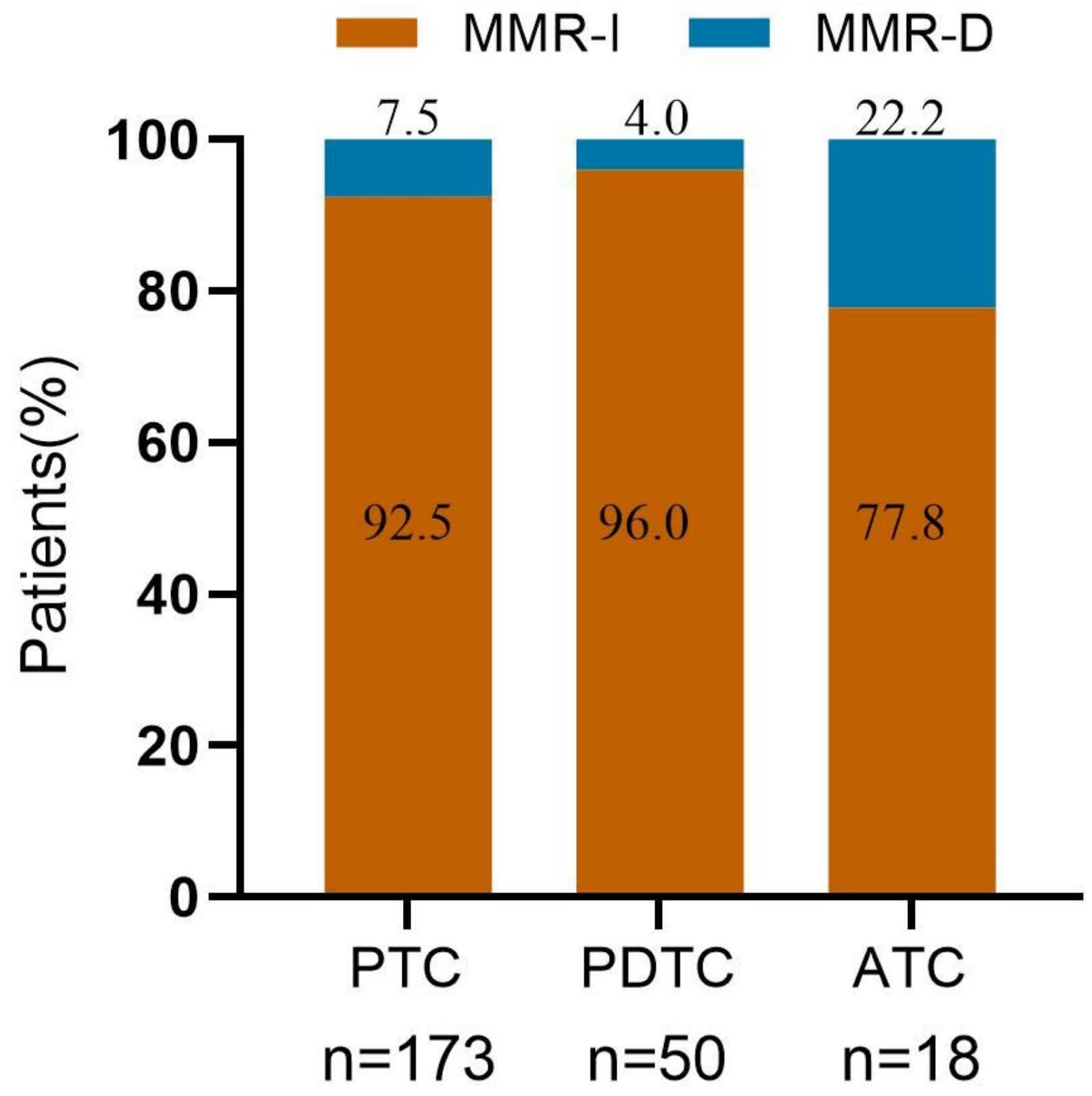

Figure 1

Proportion distribution of thyroid cancer MMR-D.

$100 \%$ stacked bar chart depicting the immunohistochemical expression pattern of each DNA mismatch repair defects (MMR-D). Tumor per type is indicated on the x-axis (PTC, PDTC, ATC). Proportion of patients are indicated on the $y$-axis, with largest proportion of tumors is ATC. PTC, papillary thyroid carcinoma; PDTC, poorly differentiated poorly differentiated thyroid carcinoma; ATC, anaplastic thyroid carcinoma. 


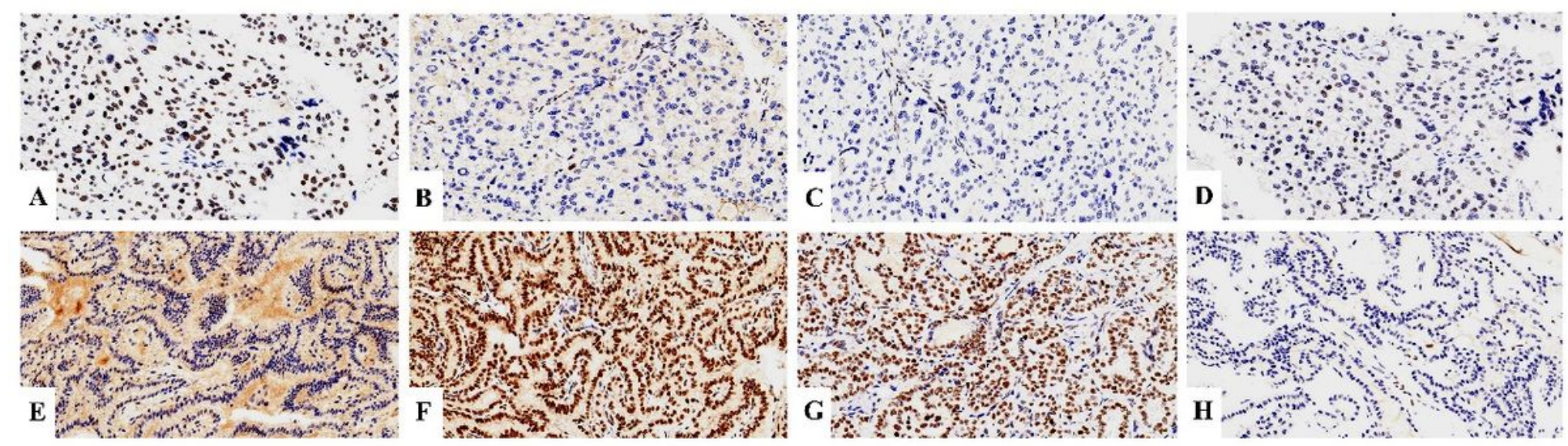

\section{Figure 2}

IHC for DNA MMR proteins (200x). The tumor showed MMR-I and MMR-D of MLH1 (A, E); MMR-D and MMR-I of MSH2 (B, F); MMR-D and MMR-I of MSH6 (C, G); MMR-I and MMR-D of PMS2(D, H). A, B, C, D are all expressions of case3. IHC, Immunohistochemistry; MMR, mismatch repair; MMR-D, MMR-protein-deficient; MMR-I, MMR-protein-intact. 

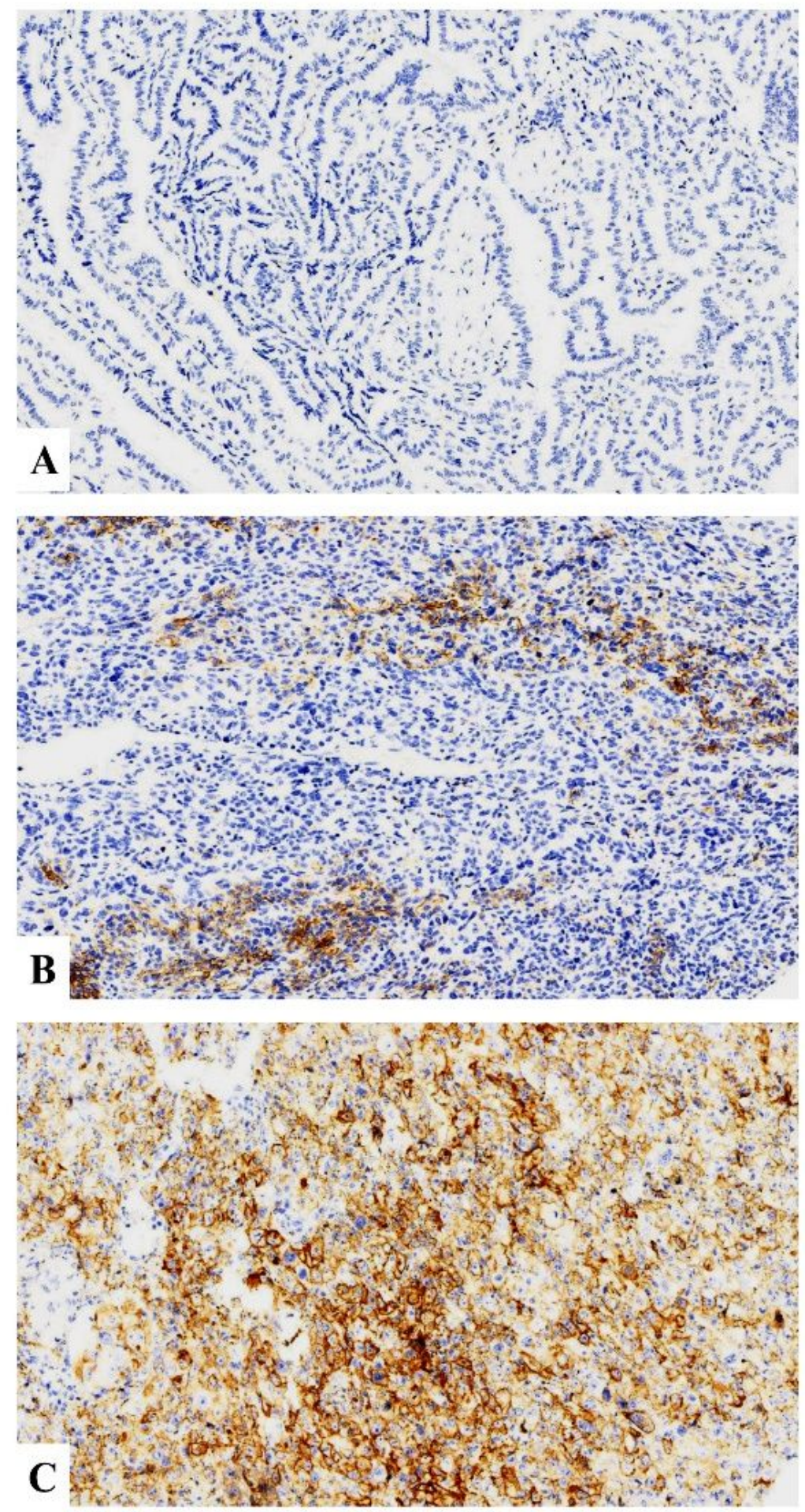

\section{Figure 3}

Representative immunohistochemistry images(200X) showing (A) negative PD-L1 expression of MMR-D patient 1 (CPS=0); $(B)$ moderate PD-L1 expression of (CPS=15) patient 11; $(C)$ high PD-L1 expression of (CPS=96.5) patient 17. CPS, combined positive score; PD-L1, programmed death-ligand 1. 
PTC

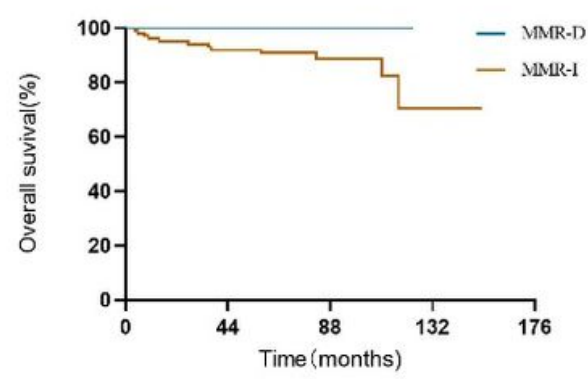

PDTC

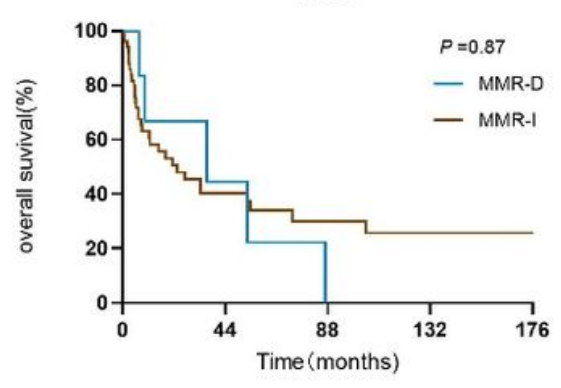

ATC

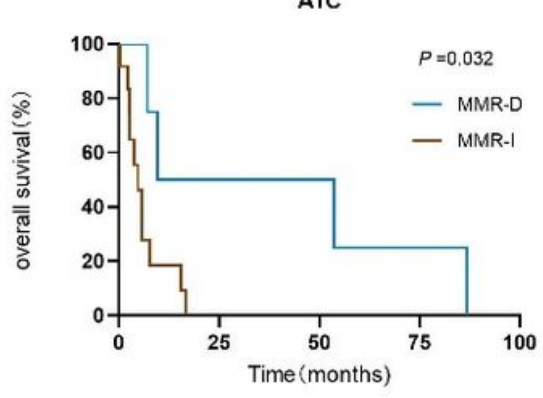

Figure 4

Kaplan-Meier survival plots presenting overall survival of (A) PTC; (B) the PDTC; and (C) the ATC.

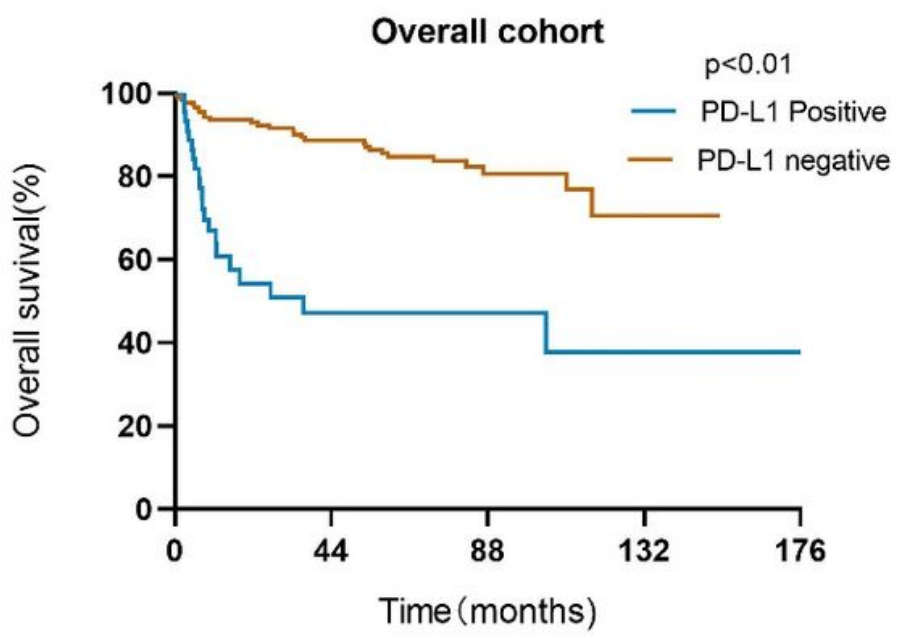

MMR-D

PD-L1-negative vs PD-L1-positive

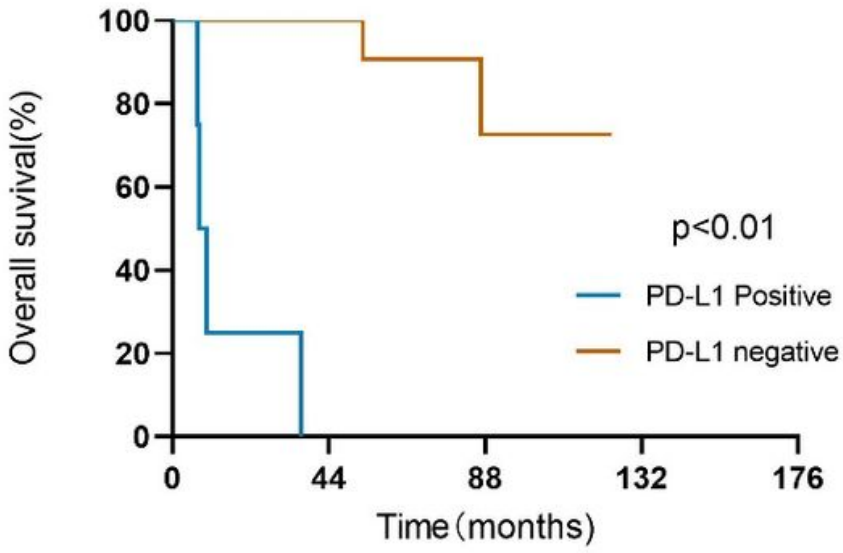

Figure 5

Kaplan-Meier survival plots presenting overall survival of (A) the overall cohort; (B) the MMR-D PD-L1negative and PD-L1-positive groups. 